\title{
Natural Products and Dermatological Hypersensitivity Diseases
}

\author{
Clayton MacDonald and Marianna Kulka \\ Institute for Nutriscience and Health, National Research Council, \\ Canada
}

\section{Introduction}

The management of dermatological hypersensitivity diseases is a lifelong struggle for most patients. Often, patients are advised to avoid triggers and aggregating factors that lead to flare ups which eventually becomes second nature to them. However, when the symptoms of these conditions become unbearable and conventional medicine no longer provides relief, an increasing proportion of allergy patients are looking to alternative treatments for comfort. Natural products are compounds isolated from natural sources (usually plants or animals) that have potentially beneficial bioactivity. However, many types of compounds can be defined as natural bioactives including synthesized molecules that are based upon naturally occurring compounds. As such, we will define the term "natural bioactive" as any compound whose parent compound structure occurs in nature. Medical research is exploring these compounds as potential treatment sources for a myriad of conditions, including the dermatological hypersensitivity diseases. With the growing interest in natural health products it could be possible that disease sufferers, by self exploring alternative treatments, are potentially leading the search towards the next new approved and medically accepted treatment.

\section{Current treatments and management in dermatological hypersensitivity diseases}

The management of atopic and hypersensitivity diseases are initially addressed by life style modifications. With all hypersensitivity diseases, be it food allergies, contact hypersensitivity, or allergic asthma, suffers quickly become aware of their disease triggers and begin a lifelong course of avoidance (Custovic et al., 1998). Unknown triggers can be identified medically using a skin prick/patch test. This involves a controlled dermal exposure to the known and the most frequent allergens, and triggers are identified from the resultant skin reactions $(\mathrm{Li}, 2002)$. Pharmacological treatments are added into the treatment schedule as the severity of disease progresses, following well-developed treatment ladders (algorithms) (Schmitt et al., 2008). As the patient moves into the stronger classes of treatments in these schedules, the associated side effects become more severe, influencing treatment decisions, ultimately compliance rate and exploration of alternative treatments.

\subsection{Life style modifications and diet}

The effect of diet on allergies and atopic diseases mitigation has been well studied, but has produced conflicting results (Allan \& Devereux, 2011; Devereaux \& Yusuf, 2003; Finch et al., 
2010; Wichers, 2009). In children with a family history of atopic diseases, research has been focused towards the effects of maternal diet during pregnancy, lactation, and then subsequently in the infant when and which foods are introduced. Of particular interest is the effect of probiotics on the development of allergies which will be discussed below (section 4.2.4). In patients with food allergies triggers are eliminated from the diet, however other foods have been suggested which might be beneficial to allergy suffers. Some of these compounds include poly-unsaturated fatty acids (PUFA); Vitamins C (Chang et al., 2009), D, $\mathrm{E}, \mathrm{Zinc}$, Selenium. However, these findings have been meet with mixed results (Finch et al., 2010).

\subsection{Medical treatment}

Medical treatments are initiated as the severity of symptoms become worse and the disease becomes intolerable (Schmitt et al., 2008). For each condition, drug classes have been recommended to be added in a specific order/time in the treatment schedule. However, due to the nature of these conditions treatment is individually tailored depending on patient response and their tolerance of the side effects. These patients follow a defined treatment plan consisting of pharmacological classes, based on their indications and complications. When treatment is initiated for a patient, the success of treatment always needs to balance with the side effect the treatment has on patient quality of life. (R. Finkel et al., 2009). The following is a brief overview of some conventional treatments for hypersensitivity disease such as sterioids and anti-histamines. Some of these compounds originated from natural sources but have been modified extensively to improve both their efficacy and potency. As such, these medications are not strictly considered "naturally sourced." In section 3 below, we will address "naturally sourced" treatments for comparison.

\subsubsection{Corticosteroids}

Corticosterioids are a class of steroid hormones that are frequently used as a first line treatment in many immunological and dermatological diseases (Richard Finkel, 2009). They can be classified as short to long acting (1-55+ hours) and are applied topically or systematically. They are very effective at mitigating inflammation; however, their side effects limit their long term use. Many of the new treatments are being sought as corticosteroids sparing alternatives (Del Rosso \& Friedlander, 2005).

Mechanism of Action: Corticosteroids bind intracellular receptors forming dimers that bind to the glucocorticoid response element of the promoter region of steroid responsive genes, which up regulates 10-100 genes (Bolognia et al., 2008). They also act by inhibiting nuclear factor $\mathrm{kB}(\mathrm{NF}-\mathrm{kB})$ which dramatically decreases the inflammatory response through the down regulation of certain cytokines, cell adhesion molecules and other inflammatory mediators. (Ex: TNFa, GM-CSF, several interleukins (ex. Il-1, IL-2, IL-6, Il-8); Intercellular adhesion molecule-1 and E-selectin; cyclooxygenase, etc). (D'Acquisto et al., 2002; Richard Finkel, 2009)

Topical Benefits: Reduced itching, improvements in sleep, appearance of skin, self-esteem and quality of life (Miller \& Eichenfield, 2006):. Side effects(Miller \& Eichenfield, 2006) Short Term - stinging on application (for potent preparations); Medium to Long Term - local complications (i.e. skin thinning, striate, glaucoma from periocular use, contact sensitization and tolerance), etc. ; Systemic effects - suppression of the hypothalamic-pituitary-adrenal axis, Cushing's syndrome, decreased immunity. 
Systemic Benefits (Miller \& Eichenfield, 2006): Relief from itching, skin redness and infiltration and reduced oozing; Side Effects(Miller \& Eichenfield, 2006): Short term increased appetite, psychosis and dyspepsia; Long term - hypertension, osteoporosis, adrenal suppression, striate and muscle atrophy, Cushing's Syndrome, decreased immunity.

\subsubsection{Emollients}

Emollients are creams designed to alleviate the symptoms of pruritus in dermatitis (Bolognia et al., 2008). They are normally applied daily and act by coating the skin and creating an artificial barrier. They are composed of either water free or water-in-oil ointments with urea $(10-20 \%)$ or lactic acid (5-12\%). The underlying principle of this treatment is to 'correct' the barrier defect of the skin in AD. Benefits: Reduce skin dryness, itching and penetration of skin by irritants and allergens; prevention of skin cracking; possible reduced need for topical corticosteroids, possible enhanced response when used with topical corticosteroids. Side Effects: Possible stinging on application (R. Finkel et al., 2009).

\subsubsection{Topical calcineurin inhibitors}

These compounds are among the newest class of immunomodulatory compounds that have been approved for use in inflammatory skin diseases (2000) (Grassberger et al., 2004). Members of this class include Pimecrolimus, Tacrolimus and Ascomycin. All originated as natural products isolated from the fermentation products of the bacteria Streptomyces $s p$. (Richard Finkel, 2009). This class has the advantage of treating AD refractory to corticosteroids and reducing the amount of corticosteroids required in severe cases (Spergel \& Leung, 2006).

Mechanism of Action: Inhibits calcineurin phosphatase by binding to FK506 binding protein which then complexes to calcineurin preventing its activation (Assmann et al., 2000). Activated calcineurin dephosphorylates the cytoplasmic subunit of the nuclear factor of activated T cells (NFAT), which then translocates to the nucleus where it forms a complex that assists in transcription of numerous cytokines (ex. Th1: IL2, INFY; Th2: IL4, IL5) (Grassberger et al., 1999; Sakuma et al., 2001).

Indications: (Bolognia et al., 2008)

Pimecrolmus - Mild to moderate atopic dermatitis, other inflammatory dermatoses Tacrolimus - Moderate to severe atopic dermatitis, other inflammatory dermatoses Benefits: Reduced itching and improvements in sleep, appearance of skin, self-esteem and quality of life (Grassberger et al., 2004; Miller \& Eichenfield, 2006)

Adverse Effects

Short term - mild stinging or burning upon application; normally improves after a week Long term - (>5 years) - Tacrolimus: safety unknown, use with caution with excess exposure to UV light; Pimecrolimus: safety profile based on 5 years of use appears good.

\subsubsection{Immunomodulators}

This class of drugs/compounds function by attenuating the immune response underlying the hypersensitivity reaction. Some of these compounds have been used as immunosuppressants in transplant medicine while others are either components of the immune system or a new class of treatments known as 'biological agents' which are 
artificially created monoclonal antibody designed to target errant members of the immune system (R. Finkel et al., 2009). Interestingly some of the immunosuppressants have their origin as natural products including: cyclosporine (isolotaed from fungus Tolypocladium inflatum), mycophenolate mofetil (isolated from fungus Penicillium stoloniferum) tacrolimus (isolated from Streptomyces tsukubaensis) as well as others (R. Finkel et al., 2009).

\section{Interferon $\gamma$}

Was investigated for use in atopic dermatitis due to its pathological dysregulation, and was found to be effective in short term (Hanifin et al., 1993) and long term studies (Stevens et al., 1998). However, its low response rate and high costs deter its regular use and implementation.

\section{Biological Agents - Monoclonal Antibodies}

These agents are biologically engineered antibodies directed against specific targets in the immune system. Some of these agents have made it to market for specific conditions (see table1). Omalizumab is a humanized mouse monocolonal antibody targeting the IgE Fc Region. It binds free IgE but not IgE bound to FceRI on masts cells, so in this way it sequesters free $\operatorname{IgE}$ without activating bound $\operatorname{IgE}$ and causing mast cell degranulation (Presta et al., 1993). Omalizumab has been approved by the FDA for use in severe recalcitrant asthma (Strunk \& Bloomberg, 2006) and has been investigated for severe cases of atopic dermatitis with positive results (Lane et al., 2006).

\begin{tabular}{|lll|}
\hline AGENT & TARGET / MOA & CONDITION \\
\hline Alefacept, Efalizumab & T-cell activation, & Psoriasis \\
Etanercept, Infliximab, & TNFell trafficking & \\
Adalimumab & TNFa & Psoriasis \\
Anakinra & CD20 (B-cells) & Rheumatoid arthritis \\
Rituximab & B-cell mediated skin diseases \\
\hline
\end{tabular}

Table 1. Examples of Biological Agents employed in Dermatological Conditions Immunosuppresants: Cyclosporine, methotrexate, Mycophenolate mofetil

These drugs act by modulating different functions of the immune system and decreasing their activity. These drugs while very potent in activity require caution in use, because of associated side effects including nephro-, neuro-, and hepatictoxicity (R. Finkel et al., 2009).

\subsubsection{Other medical treatments}

\section{Anti-Microbial:}

This class of pharmaceuticals are commonly used against infections caused by pathological secondary barrier defects in the epidermis. Infections can be caused by intense scratching leading to excoriations or due to immune suppression from other treatments. Common infections associated with atopic dermatitis include bacterial (S. aurues), viral (Molluscum contagiosum, HSV) and fungal (Candida sp., Malassezia sp.) (Bolognia et al., 2008). 


\section{Retinoids}

Retinoids are related to Vitamin A and act by binding nuclear receptors (RAR, RXR) which directly and indirectly up regulate gene expression responsible for immune and inflammatory responses and proliferation and differentiation of epithelial cells (Bolognia et al., 2008). Retinoids require careful consideration before use due to side effects including local effects, systemic, psychological but more importantly teratogenic effects (David et al., 1988).

\section{Anti-Histamines}

This class of drugs has multiple therapeutic targets including allergic and inflammatory conditions, motion sickness and nausea, gastric acid secretion and others (Richard Finkel, 2009). They play a role in urticaria prevention (Jauregui et al., 2007) and symptomatic treatment in other mast cell conditions (Herman \& Vender, 2003; Montoro et al., 2007) especially for edema control and pruritus.

\section{Mast Cell Stabilizers}

Members of this class of drugs include cromolyn and nedocromil, and are used in mast cell mediated allergic conditions. They function by inhibiting the $\operatorname{IgE}$ mediated release of histamine by stabilization of the membrane (Corin, 2000).

\subsubsection{Other treatments}

In addition to medicinal treatments prescribed by practitioners are a series of physical and alternative treatments. Very popular with dermatological treatment is the use of UV light and tanning beds, especially for psoriasis. Although the mechanism of action is unknown, it is thought that UV activates Psoralen which inhibits cellular proliferation. In certain conditions practitioners may prescribe Ichthyotherapy in which small fish (doctor fish) are employed to remove dead skin from lesions. Coal tar (mixture of hydrocarbons) is used as an emollient and remains a popular treatment in many dermatological centers (Bolognia et al., 2008).

\section{The use of Complementary and Alternative Medicine (CAM)}

Complementary and Alternative Medicine (CAM): Group of diverse medical and health care interventions, practices, products or disciplines that are not generally considered as part of conventional medicine (NCCAM, 2011)

Complementary Medicine: Any of a range of medical therapies that fall beyond the scope of scientific medicine but may be used alongside it in the treatment of disease and ill health (NCCAM, 2011)

Alternative Medicine: Medical therapies that are used in lieu of conventional therapy (NCCAM, 2011),

(Note: There are many definitions that have been put forward for CAM, these are the ones designated by the National Center for Complementary and Alternative Medicine (USA)).

Recognition of the rising interest and potential importance of Traditional Medicine (TM) and CAM lead the WHO to survey its membership on their respective national attitudes and regulatory status of this branch of health care. They found in 2005 that $71 \%$ of respondents have laws, legislative mandates and National regulatory bodies in place for TM/CAM (WHO, 2005). In 1991, the United States created the Office of Alternative Medicine to 
scientifically scrutinize alternative health practices for the benefit of public and health professionals knowledge. By 1998, due to increasing interest of the subject, this department was expanded into the National Center for Complementary and Alternative Medicine as a member institute of the United States Institutes of Health. It was from this department that a systematic classification of Complementary and Alternative Medicines was formed and grouped into 5 categories (Molassiotis et al., 2005), see Table 1. It is from the biological based therapies and the Alternative Medical systems that sources of natural products are being explored for as potential disease treatments and being entered into clinical trials. It should be noted that treatments from the other groups have entered clinical trials for certain conditions with mixed results including massage (Schachner et al., 1998), acupuncture (Salameh et al., 2008), meditation (Chida et al., 2007), prayer and others.

\begin{tabular}{|lll|}
\hline CLASSIFICATION & EXAMPLES \\
\hline I & Alternative Medical Systems & Traditional Chinese Medicine, Ayruveda \\
II & Mind-Body Interventions & Meditation, Prayer, Healing or Support Groups \\
III & Biological Based Therapies & Herbs, Dietary Supplements, Vitamins \\
IV & Manipulation and Body Based & Massage, Chiropractive, Osteopathy \\
V & Energy Therapies & Qi Gong, Reiki \\
\hline
\end{tabular}

Table 2. Classification of CAM devised by Center for Complementary and Alternative Medicine

\subsection{Demographics of CAM use in industrialized nations}

There has been a well-recognized trend in the increasing use of CAM among the general public (Harris \& Rees, 2000; Su \& Li, 2011). In the 2002 US National Health Interview Survey (NHIS) of 31,044 adults, 36\% of adults reported using CAM in the previous 12 months, and if a life time prevalence was included, this figure rose to $50 \%$ (Barnes et al., 2004). The results from the 2007 survey saw the 12 month prevalence figure rise to $38.6 \%$ and among those positive respondents, the most common CAM was listed as 'natural products' (Barnes et al., 2008). Earlier smaller scale national surveys conducted by Eisenberg et al. found prevalence rates of $33.8 \%$ in 1990 and $42.1 \%$ in 1997, although these values are higher (possibly due to the small samples size) it is generally agreed that CAM use is continually increasing (Eisenberg et al., 1998). The NHIS surveys identified some demographic characteristics common among users which have been confirmed from other studies. CAM use is more prevalent among women, adults with higher education, those who engaged in leisure time and physical activity, those who had one or more existing health conditions and have made frequent medical visits in the past year (Barnes et al., 2008; Eisenberg et al., 1998; Metcalfe et al., 2010; Sirois \& Gick, 2002). Other identified factors are higher socioeconomic status, being married, those who wished to take a more active role in health care decision making and most interestingly those with a chronic health condition (Metcalfe et al., 2010; Wiles \& Rosenberg, 2001). The popularity of CAM use is also recognized in other industrialized countries ; the rates for Canada are estimated at 12-20\% (Gavin \& Boon, 2005) and 46\% in Germany and $49 \%$ in France where alternative treatments are well engrained in the national consciousness (Fisher \& Ward, 1994). The trend of increasing CAM can be identified from Germany (West) with its 12 months prevalence almost doubling since the 1970's (See Figure 
1) (Dixon et al., 2003). It should be kept in perspective when looking at the trends of TM/CAM use that (as defined by the WHO) up to $80 \%$ of the world's population uses $\mathrm{TM} / \mathrm{CAM}$ as their sole source of health care in the places where Western health care is inaccessible ((World Health Organization., 2009).

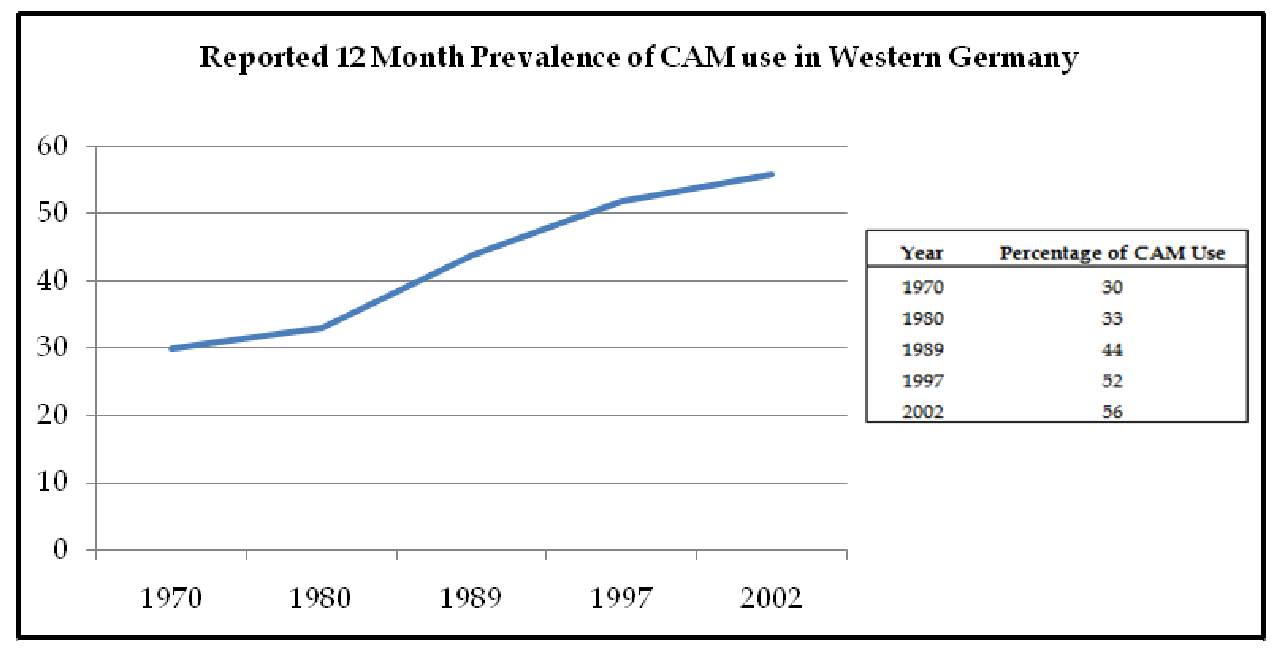

Fig. 1. Reported Use of CAM in Western Germany from 1970s to 2002

\subsection{Patient and user attitude toward CAM}

There have been many attempts to identify the reasons and motivations as to why members of the public are exploring alternative options for their well-being and health care. A large European study of 956 Cancer patients in 12 countries, found a prevalence rate of CAM use of $38.2 \%$ (Range of $14.8 \%$ to $73.1 \%$ ). From those who reported using CAM therapy they were investigated first, for their motivation and second, how found out about them. The most common motivation for CAM use was to increase their body's ability to fight disease (50.7\%), followed by improved physical well-being (40.6\%), and improvement of emotional well-being $(35.2 \%)$. Sources of information about CAM were identified as friends (56.5\%), family (29.1\%), media $(28.4 \%)$ and only $18.6 \%$ said their physician was the source (Molassiotis et al., 2005). Use of CAM is associated with greater number of physical symptoms and with symptoms of greater intensity, longer disease duration (Sirois \& Gick, 2002). The reasons for people to explore alternative treatment are varied, but what should be recognized is that are they exploring them. By having members of the public vetting these treatments in terms of personal satisfaction gives health care workers a unique opportunity by looking at the usage trends in members of the public as potential treatments sources.

\subsection{Health care practitioners attitude towards CAM}

The number of visits to practitioners of alternative therapies is now higher than the number of visits to all US primary care physicians (Pagan \& Pauly, 2005). Physician and health care professionals response to CAM has been varied with differences depending on country, 
region, age, experience and even sex. In a literature review by Sewitch et al found that characteristics of physicians whom are more likely to recommend CAM are younger, female, less experienced; while those less likely to recommend CAMs were older, male, more experienced physicians (Sewitch \& Rajput, 2010). Older physicians are less likely to use CAMs themselves or recommend it to their family (Kurtz et al., 2003). It should be noted that physicians are the most skeptical and least likely to recommend CAMs to patients, of all members of the health care profession. Rural health care providers offered CAM more frequently than their urban colleagues (Brems et al., 2006). Between $60-80 \%$ of surveyed physicians express interest in CAM therapy (Corbin Winslow \& Shapiro, 2002; Milden \& Stokols, 2004) but few as $14 \%$ have recommended it their patients. Among physicians there is prejudice about the different types if CAMs, established practices such as acupuncture, chiropractor tend to be surveyed as the most likely to be beneficial to the patient; While reiki, bioelectromagnetics, aromatherapy have been ranked by doctors as having the least potential to be beneficial or event harmful to the patient (Levine et al., 2003).

\subsection{CAM and allergies}

In a German study of 351 subjects with hypersensitivity (hay fever, asthma, atopic eczema, food allergies), 93 (26\%) were found to be users of CAM. Of the 93 users, $94 \%$ previously were treated conventionally before starting CAM while 3 users used CAM before starting conventional treatment. Of those treated conventionally the majority (85\%) were treated more than 10 years before trying CAM, they also score the efficacy of conventional medicine lower in their experience. Their reported motivations for using CAM were: conviction that CAM has less side effects $(78 \%)$, wish to try everything $(72 \%)$, unsatisfying results from conventional medicine (66\%), and belief CAM is more natural (61\%) (Schafer et al., 2002) . In a review of 7 surveys of dermatological patients who used CAM they found life time prevalence of 35-65\% (Ernst, 2000); among all the surveys they found severity of illness and length of disease had the greatest influence on CAM use. In Europe approximately $30 \%$ of patients with allergies report using CAM and this rises to approximately $50 \%$ of patients whom required in-patient treatment (Schafer, 2004). The use CAM is related to the severity of the symptoms of their conditions, patients who identify with having poor control are more likely to explore alternative treatments.

\section{Search for natural products}

Natural products are compounds that have been isolated from a living organism that have been found to be biologically active. A large proportion of the medicines in our current pharmacopeia have either originate as natural products or are inspired by a natural product using it chemical structure as framework on which to build on (Newman \& Cragg, 2007). These compounds are being explore for, from all facets of nature including CAMs, our foodstocks, and on an increasing scale the marine sources. The remainder of the chapter will explore some of the natural products undergoing clinical trials for the treatment of Atopic dermatitis. Atopic dermatitis was selected due to its complex pathology, its association with the atopic march and the availability of an animal model which will be discussed below. The test compounds will be discussed below in the context of atopic dermatitis; however some of them are being tested in other related dermatological conditions. 


\subsection{Clinical trials}

Any medicinal compound before entering into an approved treatment system (i.e. National Pharmacopeia) requires rigorous study and clinical trials, which have a defined set of trial steps, before they can be approved for use by National Regulatory bodies. In the United States this task is mandated by the Food and Drug Administration (FDA), in Canada by Health Canada and in the European Union by the European Medicines Agency (Rawson, 2000). All drug approvals required an evidence based approach to qualify their efficacy, evaluate the potential toxicity, and to prevent any unforeseen harm to patients. It is interesting to note that estimates now have the cost of marketed drugs from the R\&D stage to consumer use at 500 million to 1 billion dollars and at a time frame of up to 10-15 years (DiMasi et al., 2003). Only about 1 out of 1000 drugs from the animal testing stage (or preclinical phase) make it into clinical trials and from there only 1 in 5-10 eventually become approved. In this manner only 21 new drugs were approved by the FDA in 2010, 25 in 2009 and 21 in 2008 (Kaitin \& DiMasi, 2011). However if natural compounds are identified from CAM treatment sources already employed by members of the public they may provide new treatment options which can enter rigorous evidence based trials which have already been vetted by members of the public.

Pre-Clinical Studies / Phase 0: Pre-clinical studies are conducted as In vitro (cell culture) and In Vivo (animal studies) as initial investigations into suspected potential biological activity. Phase 0 studies are human trials using microdoses to determine if its biological effects are

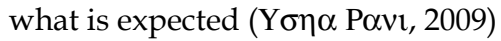

Phase I: Small scale study of 20-100 healthy subjects, testing the safety, pharmacodynamics and pharmacokinetics of the study compound (Streiner \& Normam, 2009), consists usually of either single or multiple ascending doses trials.

Phase II: Following the safety approval of drugs in Phase I, these are a small studies of 50-300 diseased subjects, designed to assess dosing requirements, efficacy, (Streiner \& Normam, 2009) and safety profiles in people with the condition.

Phase III: Randomized controlled multicenter trials on large group of diseased patients with the target condition, this study are used to determine if the study compound has targeted therapeutic effects (R. Finkel et al., 2009).

Phase IV: These studies occur after the drug has enter the market and is known as PostMarketing Surveillance. They determine if any adverse events happen in large group of patients which were not previously identified. This phase is important is identifying any rare adverse events which occur in large treatment populations. This monitoring is responsible from removing from market approved drug which later have been found to be potentially harmful, examples are Troglitazone (Cohen, 2006; Gale, 2006) and Vioxx (Karha \& Topol, 2004).

\subsection{Atopic Dermatitis}

Atopic dermatitis (AD) has been recognized since at least the 1500s (Wallach et al., 2005) with its first formal medical description in 1933(Wise \& Sulzberger, 1933). This condition is currently a popular target of medical research due to its increasing incidence (Peroni et al., 2008; H. Williams, 1992), distressing rash and intense pruritic symptoms(Hanifin \& Rajka, 1980), leading to general negative effects on the patients quality of life (Kiebert et al., 2002) and its being refractory to treatment, along with a host of other reasons. With is long recognition in recent medical history, has led to many treatment options being made available. If any new product is found to possess immunomodulatory effects they tend to be 
investigated as possible treatments for AD. The remainder of this chapter will look at Natural Products and Natural Preparations undergoing clinical trials for the treatment of AD.

\begin{tabular}{|ll|}
\hline PHASE & PARAMETERS \\
\hline Pre-Clinical & $\begin{array}{l}\text { In-Vitro (Cell Culture) and In Vivo (Animal Studies), determines biological } \\
\text { activity, toxicity, etc }\end{array}$ \\
I & $\begin{array}{l}\text { Small group health subjects; Pharmacokinetic and Pharmacodynamid } \\
\text { properties, Single Ascending Dose, Multiple Ascending Doses }\end{array}$ \\
II & $\begin{array}{l}\text { Small group diseased subjects, determine dosing requirements, drug } \\
\text { efficacy }\end{array}$ \\
III & Larger group diseased subjects; Randomized Controlled Multicenter trials \\
IV & Post Marketing Surveillance Trial \\
\hline
\end{tabular}

Table 3. Phases of Clinical Trials

\subsubsection{Animal Models: NC/Nga mice}

One of the advantages of research into treatment for atopic dermatitis has been the development of an animal model that has been accepted to be representative of the disease (Suto et al., 1999). Using this model, researchers are able to easily test products prior to proceeding to human clinical trials. NC/Nga mice are a strain that originated from the Japanese fancy mice (Nishiki-Nezumi), established as an inbred strain in 1955 (Matsuda et al., 1997). Researchers noticed the development of spontaneous dermatitis like lesions that appeared just before or after weaning but the cause and pathogenesis had been unclear. A study was conducted to compare these lesions to those of human Atopic Dermatitis (Suto et al., 1999). Mice raised in specific pathogen free (SPF) air controlled bioclean rooms did not develop lesion, but when moved to air uncontrolled rooms, spontaneously several different type of lesions developed after 8 weeks. These mice developed clinical signs similar to AD: itching, erythema and hemorrhage, edema, superficial erosion, deep excoriation, scaling and dryness of the skin, and retarded growth. Infectious causes were ruled out by co-rearing with BALB/c mice which did not develop lesions. The histopathological changes which were consistent with Atopic Dermatitis as well as clinical labs values such as IgE hyperproduction (Matsuda et al., 1997), overproduction of Th2 specific cytokines (Suto et al., 1999; Vestergaard et al., 1999). A literature search conducted in May 2011 resulted in 245 and 185 articles when the following keywords were used together: NC/Nga Mice, Atopic Dermatitis.

\subsubsection{Animal trials}

The following is a list of compounds (albeit not exhaustive) investigated using the NC/Nga mice model as potential treatments for Atopic Dermatitis. All were oral feeding studies in which the test compound was compared to a control. The efficacies of test compounds were determined by the improvement in symptoms of skin erythema, edema, excoriations, dryness, and scratching behavior. Other parameters measured depended on the trial and included plasma Ig levels, cytokines and chemokine profiles, and evaluation of skin biopsies. All of these studies had positive outcomes based on the design parameters and were recommended by their research teams for use in human clinical trials. 


\section{Rumex Japonicus Houtt}

Rumex is an herb used in the traditional medical systems originating from Eastern Asian countries (Japan, Korea, China) for the treatment of various skin diseases including AD (H. S. Lee et al., 2006). Previous studies have shown that it contains components with antioxidant and antibacterial properties (Elzaawely et al., 2005). Identified Bioactive compounds include anthraquinone derivatives: emodin, chrysophanol, physcion. These compounds studied from other natural sources are reported to have antibacterial, antifungal, antiinflammatory, immunosuppressive and antiviral properties (H. S. Lee et al., 2006) After 42 days, mice treated with the test compound were found to have significant decreases in the severity of all symptoms when compared to the control, particularly the scratching behavior, which is the most distressing symptom of AD. There was a decrease in plasma IgE and IL4 (which mediate type I hypersensitivity) and noticeable decrease of inflammatory changes in the skin biopsies. The results were more pronounced in the higher concentration groups indicating this compound causes a dose response (H. S. Lee et al., 2006).

PG 102 - Actinidia Arguta

Actinidia Argurta, commonly known as Hardy Kiwi, is a fruit native to Korea, Northern China and Siberia. Compound PG102 and isolated from this fruit by Park et al. in 2005 and found to have oral immune modulating effects in mice (Park et al., 2005). A follow up study conducted to determine the effect on the NC/Nga mice model (Park et al., 2007), found that after 9 weeks, PG102 showed statistically significant beneficial effect on AD symptoms and scratching behavior, while noted immunomolecular effects showed a decrease in IgE, IgG, IL4 while IL12 was increased. Other reported effects including the prevention of eosinophilia, decreased levels of eotaxin and TARC, inhibiting the infiltration of inflammatory cells into the dermis, preventing the thickening of the epidermis and dermis and reduced expression of Th2 mediated cytokines and chemokines (Park et al., 2007). All of these effects are beneficial in attenuating the pathophysiological changes seen in Atopic dermatitis. Kim et al. tested the extract for efficacy compared to dexamethasone (corticosteriod) and tacrolimus and found PG102 attenuated the physical symptoms of AD similar to dexamethasone and more efficiently than tacrolimus. It also had positive effects on the molecular inflammatory markers as well (ex. IgE, IL4, INFY and others). However, all three compounds affected the physical changes in the dermis in a similar manner (Kim et al., 2009). The initial results indicated this compound shows a promising potential for future use as an oral dietary supplement for the long term treatment of AD.

\section{Saururus Chinensis Baill}

Saururus is a perennial herbaceous plant used in Korean folk medicine for the treatment of various conditions such as edema, jaundice, gonorrhea and used has been employed as an antipyretic, diuretic, and anti-inflammatory agent (Choi et al., 2008). It has been shown to have anti-oxidant activity (Y. S. Lee et al., 2004) and has been used in the management of various skin diseases including AD in Eastern countries. It contains flavonoids (quercetin, quercitrin, isoquercitrin, rutin) as active components which are reported as possessing number of biological effects: antiallergic, anti-inflammatory, antiviral, antiproliferative, anticarcinogenic (Scalbert \& Williamson, 2000). After 63 days this compound was found to significantly improve skin severity scores and improved itching behavior, with the higher concentration preforming better. Molecular evaluation found a decrease in $\operatorname{IgE}$ but no changes in IL4. 


\section{Lyophyllum Decastes}

Lyophyllum is an edible mushroom cultivated in Japan that is commonly known as 'Fried Chicken Mushroom'. In a previous study, 11 polysaccharide extracts were found to have anti-tumour activity (Ukawa et al., 2000) particularly (1-3)B-D-Glucan and (1-6)B-D-Glucan. In 2006, it was examined for its potential effect on the AD mice model (Ukawa et al., 2007) using a 6 week feeding study. At the end of the study the treatment group had significant decreases in skin severity scores, as well as decreases in serum IgE, Histamine, and IL-4.

\section{Persimmon Leaf Extract}

Persimmon is the edible fruit of the Diospyros kaki Thunberg (Ebenanceae) tree which grows in China, Korea and Japan (Matsumoto et al., 2002). Kaempferol, a flavonoid contained in the leaf, was found to inhibit antigen and calcium ionophore A23187 induced histamine release. Kaempferol-3-glucoside (astraglandin) has been shown to have antipruritic effects(Ishiguro \& Oku, 1997). Kotani et al. found the leaf extract inhibited the release of histamine from human basophilic cell line KU812 (M Kotani, 1999) promoting them to study the effect on NC/Nga model (Kotani et al., 2000). A 14 week oral feeding study using both Persimmon Leaf extract and Astraglandin alone found both were effective in decreasing the severity of skin scores, inhibiting IgE, IL4, IL13 and Histamine release (Kotani et al., 2000). A similar follow up study was conducted confirming these earlier results and included measurement of Transepidermal water loss (TEWL) (Major pathology in $\mathrm{AD}$ due to dermal barrier dysfunction) and was found to be improved by the extract (Matsumoto et al., 2002).

\section{Konjac Glucomannan}

Konjac is a plant found in eastern Asia and is very popular in Japan as cooking supplement. Two compounds of interest have been isolated from this product and tested as possible treatments: Konjac glucomannan which has been tested in mice and Konjac ceramide which entered human trials (see section 4.2.4). Glucomannan, a dietary fiber isolated from the tubers of Amorphophallus konjac, is a highly viscous polysaccharide composed of glucose and mannose residues (Onishi et al., 2005). During the 1970's dietary fibers were investigated as part of the epidemiology of colon cancer (Burkitt, 1971a, 1971b). During mice feeding studies it was observed that serum IgE levels decreased and IgA and IgG increased(Lim et al., 1997) indicating dietary fibers indirectly influenced immunoglobulin production. This theory was investigated in NC/Nga mouse model during an 8 week controlled feeding trial. Skin severity symptoms were significantly improved and scratching events were decreased to $1 / 3$ to $1 / 6$ of controls. Serologically it almost totally suppressed IgE levels and decreased the total Immunoglobulin, with a noted decreased in IL-4 and INFY. Since the compound suppressed both Th1 and Th2 related cytokines it's mechanism of action cannot be attributed to Th1/Th2 polarization (Onishi et al., 2004, 2005). Follow up studies found that it decreased scratching behvaiour in a dose dependent manner (OnishiKawamotoSuzuki et al., 2007), and prevented IgE class switching in Balb/c mice following injection of keratinocyte extract (Oomizu et al., 2006). It was also found to suppress allergic rhinitis like inflammation following nasal challenge with ovalabumin (OnishiKawamotoUeda et al., 2007).

\section{Gyokuheifusan}

This is a traditional Chinese Medicine formulation that has been used for the treatment of allergic and respiratory disease (ex. infections, allergic rhinitis, asthma, and others) (Fang et 
al., 2005).This preparation contains three herbal medications: Astragalus membranaceus, Atractylodes ovata, Saposhinkovia divaricate. In a study on the immunomodulatory effects of the formulation on allergic asthma, it was found to reduce the severity of asthma through normalization of INFY/IL4 ratio (Th1/Th2 balance) (Fang et al., 2005). These results were hypothesized to extent to $\mathrm{AD}$, after a 4 week oral feeding treatment placebo control study it was found that dermatitis severity scores were improved significantly, as well as IgE and the IFNY/IL4 balance (Nakatsukasa et al., 2009).

\begin{tabular}{|c|c|c|}
\hline COMPOUND & PARAMETER IMPROVEMENT & MOLECULAR IMPROVEMENTS \\
\hline $\begin{array}{l}\text { Rumex Japonicus } \\
\text { Houtt }\end{array}$ & $\begin{array}{l}\text { Skin Severity Scores, Scratching } \\
\text { Behaviour, Skin inflammatory } \\
\text { Changes }\end{array}$ & Decrease IgE, IL4 \\
\hline $\begin{array}{l}\text { PG102 - } \\
\text { Actinidia Arguta }\end{array}$ & $\begin{array}{l}\text { Skin Severity Scores, Scratching } \\
\text { Behaviour; Prevented eosinophilia, } \\
\text { inflammatory cells entering dermis }\end{array}$ & $\begin{array}{l}\text { Decrease IgE, IgG, IL4, TARC, } \\
\text { Eotaxin; Increase IL12; Reduce } \\
\text { expression of Th2 mediated } \\
\text { cytokines }\end{array}$ \\
\hline $\begin{array}{l}\text { Saururis Chinensis } \\
\text { Baill }\end{array}$ & $\begin{array}{l}\text { Skin Severity Scores, Scratching } \\
\text { Behaviour }\end{array}$ & Decrease IgE \\
\hline $\begin{array}{l}\text { Lyophyllum } \\
\text { Decastes }\end{array}$ & $\begin{array}{l}\text { Skin Severity Scores, Scratching } \\
\text { Behaviour }\end{array}$ & Decrease IgE, IL4, Histamine \\
\hline $\begin{array}{l}\text { Persimmon Leaf } \\
\text { Extract }\end{array}$ & $\begin{array}{l}\text { Skin Severity Scores, } \\
\text { Transepidermal Water Loss }\end{array}$ & Decrease IgE, IL4, IL13, Histamine, \\
\hline $\begin{array}{l}\text { Konjac } \\
\text { Glucomannan }\end{array}$ & $\begin{array}{l}\text { Skin Severity Scores, Scratching } \\
\text { Behaviour }\end{array}$ & Decrease IgE, Ig, IL4, INFY \\
\hline Gyokuheifusan & Skin Severity Scores & Decrease IgE, IFNY/IL4 balance \\
\hline
\end{tabular}

Table 4. Summary of Treatments Tested in Animal Models

\subsubsection{Human clinical trials}

When clinical trials are conducted for Atopic Dermatitis subjective symptoms such as erythema and pruritus, must be converted to objective and uniform results so that they may be compared with other studies. The following are some of the most commonly used systems and those employed in the following studies:

Transepidermal Water Loss (TEWL) (Pinnagoda et al., 1990): This is a measure of integrity of stratum corneum's water barrier function; it provides information about the integrity of the skin, which becomes compromised in $\mathrm{AD}$ and may be influenced and improved with treatment. It is measured using tewameter, with units expressed as $\mathrm{g} / \mathrm{m}^{2} / \mathrm{h}$; with improvement indicated by a lower value.

Blood flow volume (BFV) :Measured as a parameter of inflammation using Laser Blood Flow Monitor; Arbitrary unit with improvement indicated by lower values.

Skin Color (a* Value): Erythema quantified by skin color reflectance it is measured using colorimeter

Visual Scoring - Visual judgment made by clinical investigator, scored 0-5

SCORAD (SCORing Atopic Dermatitis) (SCORAD, 1993): Standardized method for reporting dermatitis severity first published in 1993 by the European Task Force on Atopic Dermatitis, allows dermatitis severity to be reported numerically ranging from 0-103. 
SCORAD Calculation $=\mathrm{A} / 5+7(\mathrm{~B} / 2)+\mathrm{C}$

\begin{tabular}{|llr|}
\hline & PARAMETER & TOTAL SCORE \\
\hline A & SPREAD/BODY SURFACE AREA & 100 \\
\hline & Judge based on rule of 9 for body surface area & \\
\hline B & INTENSITY & \\
& Erythema (1-3) & \\
& Edema (1-3) \\
& Oozing/Crusting (1-3) \\
& Excoriation (1-3) \\
& Lichenification (1-3) & \\
\hline C & SUBJECTIVE SYMPTOMS & \\
\hline & Pruritus (1-10) & \\
& Insomnia (1-10) \\
\hline
\end{tabular}

Table 5. Parameters for SCORAD Calculation

\subsubsection{Human clinical of trials of natural products}

WBI-1001 (IPBD: 2-isopropyl-5-[(E)-2-phenylethenyl] benzene-1,3-diol)

This compound is derived from a metabolite of a unique group of bacterial symbiots of entomopathogenic nematodes. It was found to inhibit inflammatory cytokine secretion by activated $\mathrm{T}$ cells including: TNFa, INF $\Upsilon$ as well as inhibit allergic contact dermatitis in a mouse edema model (Bissonnette et al., 2010). A phase 2A, double blind, vehicle controlled study resulted in statistically significant improvement in SCORAD, pruritus, and the amount of affected body surface area. These improvements were reached after 3-5 weeks of treatment. A 12 week Phase IIb trial was conducted (NCT01098734) as of June $9^{\text {th }}$ 2011, the results are still pending publication.

\section{Konjac Ceramide}

Konjac ceramide is the second compound of interest isolated from konjac. Ceramides are a normal component of the lipid membrane, and their deficiency has been suggested as one of the pathological factors resulting in skin barrier disruption (Imokawa et al., 1991), having being previously studied in the treatment of dermatitis (Berardesca et al., 2001). Glucosylceramides are isolated, purified and produced as a nutritional supplement (Kimata, 2006) and oral intake has been found to decrease transepidermal water loss in normal adults (Miyanishi et al., 2005). Konjac due to its high concentration of ceramide was studied for its effect on $\mathrm{AD}$ as an oral supplement. Following a 4 week oral feeding trial in 50 children, the SCORAD index was significantly improved when compared to the control group. INFY and IL-12 were significantly increased while IL-4 and IL-13 were decreased indicating a skewing of the cytokine pattern towards a Th1 type. Interestingly in this study, ceramide was found to attenuate allergen specific response to HDM (house dust mite) and JCP (Japanese cedar pollen) by improving skin symptoms and wheal response but had no effect following dermal challenge of Egg white, histamine or buckwheat (Kimata, 2006).

\section{Borage Oil: Gamma-Linolenic Acid}

In patients with $\mathrm{AD}$, an abnormality in metabolism of polysaturated fatty acids (PUFA) is commonly observed (Wright, 1991). PUFA are structural components of cell membrane 
phospholipids which are important in maintaining membrane fluidity (Wright, 1991), as well as being important as precursors for pharmacologically active immunological agents (ie Eicosanoids) (R. Finkel et al., 2009). Borage oil contains a high content (24\%) of $\Upsilon$-linolenic acid (GLA) which is a metabolite of linoleic acid, one of the essential fatty acids. It is postulated an abnormality in essential fatty acid metabolism affects production of GLA and its incorporation into membranes, occurs in AD (Horrobin, 2000; Wright, 1991). Previous studies have shown GLA supplementation lead to improvements in multiple diseases including seborrheic dermatitis in children (Tollesson \& Frithz, 1993). In a small Japanese study in a pediatric population, undershirts coated with Borage oil were given to 32 children in a double-blind, placebo controlled study (Kanehara et al., 2007). After 2 weeks it was found that there was a statistically significant improvement in symptoms of itch and erythema, but no improvement papules, erosions, and trans-epidermal water loss (Kanehara et al., 2007). In a literature review of 12 trials (oral and topical) on the efficacy of Borage Oil in the treatment of AD by Foster et al. in 2010 found that 5 studies show statistically significant improvement, while 5 showed borage oil to be ineffective and 2 studies were shown only to have partial response (Foster et al., 2010). The efficacy of borage oil in the treatment of $\mathrm{AD}$ remains questionable, a previous product EpoGam used for treatment of $\mathrm{AD}$ was removed from market in 2002 in the UK when it was found to be ineffective. This product contained primrose oil which contains lower concentration of GLA then borage oil but was based on the same pathophysiologic principle(H. Williams, 2003). Borage oil while providing some benefit in some studies requires future study to determine its efficacy and it remains to be determine if it will be steroid sparing.

\section{Emollient Therapy}

Emollient therapy is a mainstay in the management of the symptoms of $\mathrm{AD}$ (Szczepanowska et al., 2008). While studies into the prevention of AD are less common, Simpson et al. proposed that 'skin barrier protection from birth using bland emollients is a safe and feasible strategy for AD prevention' (Simpson et al., 2010). This was based on the results from previous studies that found use of petrolatum early in life may be protective against $\mathrm{AD}$ development, there was trend towards increased TEWL and skin hydration before development of $\mathrm{AD}$, use of emollients in premature infants protects against skin inflammation and emollients are effective at preventing flares in established AD (Simpson et al., 2010). In 20 high risk infants (based on the ISSAC criteria (Asher et al., 2006)) emollient therapy was initiated in the first week of life in order to maintain intact skin barrier. After 2 years it was found that only $15 \%$ of subject developed AD when conservative estimates of high risk infants would be positive for AD in the range of $30-50 \%$ suggesting this treatment could have both a protective and preventative effect (Simpson et al., 2010).

\section{Probiotics}

Living or inactivated organisms that are claimed to exert beneficial effects on health when ingested are referred to as Probiotics (Schrezenmeir \& de Vrese, 2001). The use of probiotic and prebiotics in the field of allergology is a controversial subject, with the results of prenatal and postnatal supplementation for the prevention of atopic dermatitis having mixed results (J. Lee et al., 2008). Probiotic intestinal colonization is theorized to affect the Th1/Th2 immunological maturation prior to the establishment of atopic dermatitis (Gruber et al., 2010). Physiologically the normal gut milieu has an immune system that is balance between protective mucosal immunity and systemic tolerance. In food allergies the balance 
is impaired and oral tolerance of dietary antigens is not achieved. Risk Factors for the development of food allergy include immature gut barrier and type II Th2 cell skewed cytokine profile are present in early infancy. This may lead to atopic sensitization as antigen uptake is aberrant and Th2 cells further produce IL4 a cytokine essential for B cell differentiation into IgE producing cells and IL5 which is important for eosinophils . Normal bacterial flora at birth is shown to counterbalance the Th2 activity and promote oral tolerance. The predilection of bacteria to promote the differentiation of Th1 cell lineage may be due to specific CpG motif characteristics of bacterial DNA which has been show to induce polycolonal B-cell activation and secretion of Th1 Cytokines IL6, IL12 and interferon $Y$ (Passeron et al., 2006). The guts of infants born in poor areas of developing countries where allergy prevalence is lower, are colonized earlier by enterobacteria, enterococcim lactobacilli, and eubacteria and displays a higher turnover of different E. coli strains in the intestinal microflora ((Matricardi et al., 2003). In a meta-analysis of 21 studies (1997-2007) by Lee et al. (2007) containing 1898 subjects looking at Probiotics in the prevention of atopic dermatitis found a risk reduction of $61 \%$ in the development of atopic dermatitis in high risk infants (J. Lee et al., 2008). Newer studies have found conflicting results (Boyle et al., 2011) so its use remains controversial. Strains of bacteria that have been investigated include Lactobacillus rhamnosus GG (Gruber et al., 2007), Bifidobacterium lactis (Kukkonen et al., 2007), Mycobacterium vaccae and others (Matricardi et al., 2003). In studies of the use of the Probiotics following the establishment of AD has been met with mixed results. In one study it was found that while probiotics did improve SCORAD results they were not statistically significant when compared to placebo (Viljanen et al., 2005) . Other studies have shown the probiotics following established AD in children did improve SCORAD (Passeron et al., 2006) .

\section{St. John's Wort Cream}

St. John Wort is a family of plants with worldwide distribution accounting for about 370 species. It has been use as a herbal treatment for depression (Rapaport et al., 2011), ADHD (Chan, 2008) and other psychological condition, however without proven clinical effects. It has been traditionally used for the topical treatment of wounds, burns, nerve lesions and has used as a remedy for eczematous skin conditions (Schempp et al., 2000). Hypericin is a major component of St. John wort and has been found to have bioactive properties exhibiting dose dependent photosensitizing activity (Schempp et al., 2000). Hyperforin, a second compound, was found to have anti-bacterial activity (Gurevich et al., 1971). After a 7 day topical trial, the treatment compound was found to significantly improved SCORAD scores. Colony forming units of $S$. aureus were measured, and found to be decreased by the treatment compound when compared to control, however not significantly. No molecular markers of inflammation were measure in this study.

\section{Herbal Preparations - Traditional Chinese Medicine}

Multiple trials have been conducted using formulas of traditional Chinese medicine. These formulas have a long history of use and documentation within their medical systems. The difficulty in investigating these compounds are due to the manner of preparation and individuality of the treatment. In a 2007 study by Hon et al. of a five herb formulation (Flos lonicerae, Herba menthae, Cortex moutan, Rhizoma atractylodis, Cortex phellodendri) in a placebo controlled 12 week oral feeding trial found that while the treatment group and placebo group both improved symptoms there was no statistically significance between the two. However in the treatment group, the number of days of corticosteroids use during the 
month was significantly decreased, improving the quality of life of the subject (Hon et al., 2007). In a follow up study it was found the formulation suppressed brain-derived neurotrophic factor (BDNF), Thymus and activation regulated chemokine (TARC), INF- $Y$, and TNFa (Leung et al., 2008).

\begin{tabular}{|lll|}
\hline COMPOUND & PARAMETER IMPROVEMENT & MOLECULAR IMPROVEMENTS \\
\hline WBI-1001 & $\begin{array}{l}\text { SCORAD, Pruritus, Body Surface } \\
\text { Area }\end{array}$ & Inhibited TNFa, Increased INF Y \\
\hline Konjac Ceramide & $\begin{array}{l}\text { SCORAD, Transepidermal Water } \\
\text { loss, Allergen specific response }\end{array}$ & $\begin{array}{l}\text { Increased INFY, IL12; Decreased } \\
\text { IL4, IL13 }\end{array}$ \\
\hline Borage Oil & SCORAD?, Itch, Erythema & Metabolism of PUFA \\
\hline Emollient Therapy & Prevention of AD & \\
\hline Probiotics & & \\
\hline $\begin{array}{l}\text { St. John's Wort } \\
\text { Cream }\end{array}$ & $\begin{array}{l}\text { SCORAD, Decreased Staph. Aureus } \\
\text { CFU }\end{array}$ & \\
\hline
\end{tabular}

Table 6. Summary of Treatments Tested in Human Clinical Trials

\subsubsection{Approved compounds}

The calcineurin inhibitors are among the most recent example of natural products that had been identified having potential biological activity, then successfully proceeded through the clinical trial phase and have been approved for use in the treatment of AD and other dermatological hypersensitivity conditions. The following natural product concoction is the most recent treatment approved for use in AD by the FDA. Using an understanding of the pathophysiology of $\mathrm{AD}$, compounds were selected that targeted different facets of the pathology to work in concert in the treatment of AD.

Atopiclair MAS063D (Atopiclair)

Hydrolipidic cream developed for the management of Atopic dermatitis, containing moisturizing elements and natural products (Belloni et al., 2005): The agent contains a combination of the bioactive compounds from Vitis vinifera, glycyrrhetinic acid and Hyaluronic acid. Hyaluronic acid is barrier forming and hydrating agent, traditionally used as lubricant in surgery (Manuskiatti \& Maibach, 1996). It is a naturally occurring glycosaminoglycan in the body found in healthy connective tissue and induces tissue hydration (traditionally used as lubricant in other areas of medicine - ocular surgery, orthopedic surgery). Telmesterine and extracts from vitis viniferia have been found to have anti protease activities, (inhibiting harmful enzymes that exuded by damaged skin; and antioxidant effects protecting against free radicals (Belloni et al., 2005). Procyanidins found in vitis viniferia have been examined at the vascular endothelium, where they help to prevent oxidative damage, they also form a barrier to protect against elastase, collagenase, hyaluronidase, and B-glucuronidase. Glycyrrhetinic acid is a compound found to have antiinflammatory activity (Teelucksingh et al., 1990) In 2003, the first vehicle controlled, double blind study of Atopiclair was conducted in a study group of 20 subjects with contact dermatitis. Subjects applied vehicle to one arm and treatment compound to the other and were measured at 24, 48 and 72 hours. Results from this compound were promising, with 
significant improvements in Transepidermal water loss (by 50\%), Blood flow volume, Skin color, Visual Scoring. Only itch magnitude results fell below significance but showed improvement (Hongbo Zhai, 2003). In a follow up study in 2004, Atopiclair was tested in patients with Atopic Dermatitis and found significant improvement in all patients after 22 days. Statistically significant improvements were measure in total body surface area affected, Itch score, SCORAD value, and Quality of sleep. In an informal survery following the study $93 \%$ of subjects responded positively to the product (Belloni et al., 2005). Following this study Atopiclair was approved by the FDA for the use in the treatment of atopic dermatitis (Abramovitis \& Perlmutter, 2007).

\section{Conclusions}

Natural Products have been identified as potential sources of bioactive compounds used in the treatment of immune disorders. Historically some of the major and most important pharmaceutical compounds have their origin as natural products (Newman \& Cragg, 2007). Penicillin, discovered as a metabolite of mold in a petri dish, revolutionized the manner in which medicine has been practiced since wide spread implementation following World War II (R. Finkel et al., 2009). Many of the classes of treatment compounds currently being used in immunology and dermatology have originated from natural products. It might hold true that the next revolutionary treatment might likewise have its origin from the natural world, potentially being already explored by patients looking into CAMs.

It is inevitable that nature will continue to provide pharmaceutical active compounds that will be used in all practices and disciplines of medicine. It is those conducting the exploration for these compounds to keep an open mind to the possibility that an already employed alternative medicine might provide the next clue or even a source unknown.

\section{References}

Abramovitis, W, \& Perlmutter, A. (2007). Atopiclair: its position within a topical paradigm for the treatment of atopic dermatitis. Expert Rev. Dermatol, 2(2), 115-119.

Allan, K., \& Devereux, G. (2011). Diet and asthma: nutrition implications from prevention to treatment. J Am Diet Assoc, 111(2), 258-268.

Asher, M. I., Montefort, S., Bjorksten, B., Lai, C. K., Strachan, D. P., Weiland, S. K., et al. (2006). Worldwide time trends in the prevalence of symptoms of asthma, allergic rhinoconjunctivitis, and eczema in childhood: ISAAC Phases One and Three repeat multicountry cross-sectional surveys. Lancet, 368(9537), 733-743.

Assmann, T., Homey, B., \& Ruzicka, T. (2000). Applications of tacrolimus for the treatment of skin disorders. Immunopharmacology, 47(2-3), 203-213.

Barnes, P.M., Bloom, B., \& Nahin, R.L. (2008). Complementary and alternative medicine use among adults and children: United States, 2007. Natl Health Stat Report(12), 1-23.

Barnes, P.M., Powell-Griner, E., McFann, K., \& Nahin, R.L. (2004). Complementary and alternative medicine use among adults: United States, 2002. Adv Data(343), 1-19.

Belloni, G., Pinelli, S., \& Veraldi, S. (2005). A randomised, double-blind, vehicle-controlled study to evaluate the efficacy and safety of MAS063D (Atopiclair) in the treatment of mild to moderate atopic dermatitis. Eur J Dermatol, 15(1), 31-36.

Berardesca, E., Barbareschi, M., Veraldi, S., \& Pimpinelli, N. (2001). Evaluation of efficacy of a skin lipid mixture in patients with irritant contact dermatitis, allergic contact 
dermatitis or atopic dermatitis: a multicenter study. Contact Dermatitis, 45(5), 280285.

Bissonnette, R., Chen, G., Bolduc, C., Maari, C., Lyle, M., Tang, L., et al. (2010). Efficacy and safety of topical WBI-1001 in the treatment of atopic dermatitis: results from a phase 2A, randomized, placebo-controlled clinical trial. Arch Dermatol, 146(4), 446449.

Bolognia, Jean, Jorizzo, Joseph L., \& Rapini, Ronald P. (2008). Dermatology (2nd ed. / edited by Jean L. Bolognia, Joseph L. Jorizzo, Ronald P. Rapini ; associate and artwork editor, Julie V. Schaffer. ed.). St. Louis, Mo. ; London: Mosby Elsevier.

Boyle, R. J., Ismail, I. H., Kivivuori, S., Licciardi, P. V., Robins-Browne, R. M., Mah, L. J., et al. (2011). Lactobacillus GG treatment during pregnancy for the prevention of eczema: a randomized controlled trial. Allergy, 66(4), 509-516.

Brems, C., Johnson, M. E., Warner, T. D., \& Roberts, L. W. (2006). Patient requests and provider suggestions for alternative treatments as reported by rural and urban care providers. Complement Ther Med, 14(1), 10-19.

Burkitt, D. P. (1971a). Epidemiology of cancer of the colon and rectum. Cancer, 28(1), 3-13.

Burkitt, D. P. (1971b). Possible relationships between bowel cancer and dietary habits. Proc $R$ Soc Med, 64(9), 964-965.

Chan, E. (2008). St. John's Wort does not show benefit for ADHD in short trial. J Pediatr, 153(5), 724.

Chang, H. H., Chen, C. S., \& Lin, J. Y. (2009). High dose vitamin C supplementation increases the Th1/Th2 cytokine secretion ratio, but decreases eosinophilic infiltration in bronchoalveolar lavage fluid of ovalbumin-sensitized and challenged mice. J Agric Food Chem, 57(21), 10471-10476.

Chida, Y., Steptoe, A., Hirakawa, N., Sudo, N., \& Kubo, C. (2007). The effects of psychological intervention on atopic dermatitis. A systematic review and metaanalysis. Int Arch Allergy Immunol, 144(1), 1-9.

Choi, M. S., Kim, E. C., Lee, H. S., Kim, S. K., Choi, H. M., Park, J. H., et al. (2008). Inhibitory effects of Saururus chinensis (LOUR.) BAILL on the development of atopic dermatitis-like skin lesions in NC/Nga mice. Biol Pharm Bull, 31(1), 51-56.

Cohen, J. S. (2006). Risks of troglitazone apparent before approval in USA. Diabetologia, 49(6), 1454-1455.

Corbin Winslow, L., \& Shapiro, H. (2002). Physicians want education about complementary and alternative medicine to enhance communication with their patients. Arch Intern Med, 162(10), 1176-1181.

Corin, R. E. (2000). Nedocromil sodium: a review of the evidence for a dual mechanism of action. Clin Exp Allergy, 30(4), 461-468.

Custovic, A., Simpson, A., Chapman, M. D., \& Woodcock, A. (1998). Allergen avoidance in the treatment of asthma and atopic disorders. Thorax, 53(1), 63-72.

D'Acquisto, F., May, M. J., \& Ghosh, S. (2002). Inhibition of nuclear factor kappa B (NF-B): an emerging theme in anti-inflammatory therapies. Mol Interv, 2(1), 22-35.

David, M., Hodak, E., \& Lowe, N. J. (1988). Adverse effects of retinoids. Med Toxicol Adverse Drug Exp, 3(4), 273-288.

Del Rosso, J., \& Friedlander, S. F. (2005). Corticosteroids: options in the era of steroidsparing therapy. J Am Acad Dermatol, 53(1 Suppl 1), S50-58. 
Devereaux, P. J., \& Yusuf, S. (2003). The evolution of the randomized controlled trial and its role in evidence-based decision making. J Intern Med, 254(2), 105-113.

DiMasi, J. A., Hansen, R. W., \& Grabowski, H. G. (2003). The price of innovation: new estimates of drug development costs. J Health Econ, 22(2), 151-185.

Dixon, Anna, Riesberg, Annette, Weinbrenner, Susanne, Saka, Omer, Grand, Julian Le, \& Busse, Reinhard. (2003). Complementary and Alternative Medicine in the UK and Germany: Research and Evidence on Supply and Demand (pp. 128). London: AngloGerman Foundation for the Study of Industrial Society

Eisenberg, D. M., Davis, R. B., Ettner, S. L., Appel, S., Wilkey, S., Van Rompay, M., et al. (1998). Trends in alternative medicine use in the United States, 1990-1997: results of a follow-up national survey. JAMA, 280(18), 1569-1575.

Elzaawely, A. A., Xuan, T. D., \& Tawata, S. (2005). Antioxidant and antibacterial activities of Rumex japonicus HOUTT. Aerial parts. Biol Pharm Bull, 28(12), 2225-2230.

Ernst, E. (2000). The usage of complementary therapies by dermatological patients: a systematic review. Br J Dermatol, 142(5), 857-861.

Fang, S. P., Tanaka, T., Tago, F., Okamoto, T., \& Kojima, S. (2005). Immunomodulatory effects of gyokuheifusan on INF-gamma/IL-4 (Th1/Th2) balance in ovalbumin (OVA)-induced asthma model mice. Biol Pharm Bull, 28(5), 829-833.

Finch, J., Munhutu, M. N., \& Whitaker-Worth, D. L. (2010). Atopic dermatitis and nutrition. Clin Dermatol, 28(6), 605-614.

Finkel, R., Clark, M., \& Cubeddu, L. (2009). Pharmacology (4th ed.). Philadelphia: Lippincott Williams \& Wilkins.

Finkel, Richard. (2009). Pharmacology (4th ed.). Baltimore: Lippincott Williams \& Wilkins.

Fisher, P., \& Ward, A. (1994). Complementary medicine in Europe. BMJ, 309(6947), 107-111.

Foster, R. H., Hardy, G., \& Alany, R. G. (2010). Borage oil in the treatment of atopic dermatitis. Nutrition, 26(7-8), 708-718.

Gale, E. A. (2006). Troglitazone: the lesson that nobody learned? Diabetologia, 49(1), 1-6.

Gavin, J. A., \& Boon, H. (2005). CAM in Canada: places, practices, research. Complement Ther Clin Pract, 11(1), 21-27.

Grassberger, M., Baumruker, T., Enz, A., Hiestand, P., Hultsch, T., Kalthoff, F., et al. (1999). A novel anti-inflammatory drug, SDZ ASM 981, for the treatment of skin diseases: in vitro pharmacology. Br J Dermatol, 141(2), 264-273.

Grassberger, M., Steinhoff, M., Schneider, D., \& Luger, T. A. (2004). Pimecrolimus -- an antiinflammatory drug targeting the skin. Exp Dermatol, 13(12), 721-730.

Gruber, C., van Stuijvenberg, M., Mosca, F., Moro, G., Chirico, G., Braegger, C. P., et al. (2010). Reduced occurrence of early atopic dermatitis because of immunoactive prebiotics among low-atopy-risk infants. J Allergy Clin Immunol, 126(4), 791-797.

Gruber, C., Wendt, M., Sulser, C., Lau, S., Kulig, M., Wahn, U., et al. (2007). Randomized, placebo-controlled trial of Lactobacillus rhamnosus GG as treatment of atopic dermatitis in infancy. Allergy, 62(11), 1270-1276.

Gurevich, A. I., Dobrynin, V. N., Kolosov, M. N., Popravko, S. A., \& Riabova, I. D. (1971). [Antibiotic hyperforin from Hypericum perforatum L]. Antibiotiki, 16(6), 510-513.

Hanifin, J. M., \& Rajka, G. (1980). Diagnositic features of atopic dermatitis. Acta Derm Venereol (Stockh), Suppl 92, 44-47. 
Hanifin, J. M., Schneider, L. C., Leung, D. Y., Ellis, C. N., Jaffe, H. S., Izu, A. E., et al. (1993). Recombinant interferon gamma therapy for atopic dermatitis. J Am Acad Dermatol, 28(2 Pt 1), 189-197.

Harris, P., \& Rees, R. (2000). The prevalence of complementary and alternative medicine use among the general population: a systematic review of the literature. Complement Ther Med, 8(2), 88-96.

Herman, S. M., \& Vender, R. B. (2003). Antihistamines in the treatment of dermatitis. J Cutan Med Surg, 7(6), 467-473.

Hon, K. L., Leung, T. F., Ng, P. C., Lam, M. C., Kam, W. Y., Wong, K. Y., et al. (2007). Efficacy and tolerability of a Chinese herbal medicine concoction for treatment of atopic dermatitis: a randomized, double-blind, placebo-controlled study. $\mathrm{Br} \mathrm{J}$ Dermatol, 157(2), 357-363.

Hongbo Zhai, Clarissa D Villarama, Zeba Hasan Hafeez, Howard I Maiback. (2003). Efficacy of a Topical Agent, MAS063D ('Atopiclair'), in the Treatment of Sodium Lauryl Sulphate-Induced Irritant Contact Dermatitis. Exog Dermatol, 2, 301-305.

Horrobin, D. F. (2000). Essential fatty acid metabolism and its modification in atopic eczema. Am J Clin Nutr, 71(1 Suppl), 367S-372S.

Imokawa, G., Abe, A., Jin, K., Higaki, Y., Kawashima, M., \& Hidano, A. (1991). Decreased level of ceramides in stratum corneum of atopic dermatitis: an etiologic factor in atopic dry skin? J Invest Dermatol, 96(4), 523-526.

Ishiguro, K., \& Oku, H. (1997). Antipruritic Effect of Flavonol and 1,4-Naphthoquinone Derivatives form Impatiens balsamina L. Phytotherapy Research, 11, 343-347.

Jauregui, I., Ferrer, M., Montoro, J., Davila, I., Bartra, J., del Cuvillo, A., et al. (2007). Antihistamines in the treatment of chronic urticaria. J Investig Allergol Clin Immunol, 17 Suppl 2, 41-52.

Kaitin, K. I., \& DiMasi, J. A. (2011). Pharmaceutical innovation in the 21st century: new drug approvals in the first decade, 2000-2009. Clin Pharmacol Ther, 89(2), 183-188.

Kanehara, S., Ohtani, T., Uede, K., \& Furukawa, F. (2007). Clinical effects of undershirts coated with borage oil on children with atopic dermatitis: a double-blind, placebocontrolled clinical trial. J Dermatol, 34(12), 811-815.

Karha, J., \& Topol, E. J. (2004). The sad story of Vioxx, and what we should learn from it. Cleve Clin J Med, 71(12), 933-934, 936, 938-939.

Kiebert, G., Sorensen, S. V., Revicki, D., Fagan, S. C., Doyle, J. J., Cohen, J., et al. (2002). Atopic dermatitis is associated with a decrement in health-related quality of life. Int J Dermatol, 41(3), 151-158.

Kim, J. Y., Lee, I. K., Son, M. W., \& Kim, K. H. (2009). Effects of orally administered Actinidia arguta (Hardy Kiwi) fruit extract on 2-chloro-1,3,5-trinitrobenzene-induced atopic dermatitis-like skin lesions in NC/Nga mice. J Med Food, 12(5), 1004-1015.

Kimata, H. (2006). Improvement of atopic dermatitis and reduction of skin allergic responses by oral intake of konjac ceramide. Pediatr Dermatol, 23(4), 386-389.

Kotani, M., Matsumoto, M., Fujita, A., Higa, S., Wang, W., Suemura, M., et al. (2000). Persimmon leaf extract and astragalin inhibit development of dermatitis and $\operatorname{IgE}$ elevation in NC/Nga mice. J Allergy Clin Immunol, 106(1 Pt 1), 159-166.

Kukkonen, K., Savilahti, E., Haahtela, T., Juntunen-Backman, K., Korpela, R., Poussa, T., et al. (2007). Probiotics and prebiotic galacto-oligosaccharides in the prevention of 
allergic diseases: a randomized, double-blind, placebo-controlled trial. J Allergy Clin Immunol, 119(1), 192-198.

Kurtz, M. E., Nolan, R. B., \& Rittinger, W. J. (2003). Primary care physicians' attitudes and practices regarding complementary and alternative medicine. J Am Osteopath Assoc, 103(12), 597-602.

Lane, J. E., Cheyney, J. M., Lane, T. N., Kent, D. E., \& Cohen, D. J. (2006). Treatment of recalcitrant atopic dermatitis with omalizumab. J Am Acad Dermatol, 54(1), 68-72.

Lee, H. S., Kim, S. K., Han, J. B., Choi, H. M., Park, J. H., Kim, E. C., et al. (2006). Inhibitory effects of Rumex japonicus Houtt. on the development of atopic dermatitis-like skin lesions in NC/Nga mice. Br J Dermatol, 155(1), 33-38.

Lee, J., Seto, D., \& Bielory, L. (2008). Meta-analysis of clinical trials of probiotics for prevention and treatment of pediatric atopic dermatitis. J Allergy Clin Immunol, 121(1), 116-121 e111.

Lee, Y.S., Baek, Y.I., Kim, J.R., Cho, H.K., Sok, D.E., \& Jeong, H.S. (2004). Antioxidant activities of a new lignan and a neolignan from Saururus chinensisis. Bioorganic $\mathcal{E}$ Medicinal Chemistry Letters, 14, 5623-5628.

Leung, T. F., Wong, K. Y., Wong, C. K., Fung, K. P., Lam, C. W., Fok, T. F., et al. (2008). In vitro and clinical immunomodulatory effects of a novel Pentaherbs concoction for atopic dermatitis. Br J Dermatol, 158(6), 1216-1223.

Levine, S. M., Weber-Levine, M. L., \& Mayberry, R. M. (2003). Complementary and alternative medical practices: training, experience, and attitudes of a primary care medical school faculty. J Am Board Fam Pract, 16(4), 318-326.

Li, J. T. (2002). Allergy testing. Am Fam Physician, 66(4), 621-624.

Lim, B., Yamada, K., Nonaka, M., Kuramoto, Y., Hung, P., \& Sugano, M. (1997). Dietary fibers modulate indices of intestinal immune function in rats. J Nutr, 127(5), 663667.

M Kotani, A Fujita, T Tanaka. (1999). Inhibitory effects of persimmon leaf extract on allergic reaction in human basophilic leukemic cells and mice. J Jpn Soc Nutr Food Sci, 52, 147-151.

Manuskiatti, W., \& Maibach, H. I. (1996). Hyaluronic acid and skin: wound healing and aging. Int J Dermatol, 35(8), 539-544.

Matricardi, P., Bjorksten, B., Bonini, S., Bousquet, J., Djukanovic, R., Dreborg, S., et al. (2003). Microbial products in allergy prevention and therapy. Allergy, 58(6), 461-471.

Matsuda, H., Watanabe, N., Geba, G. P., Sperl, J., Tsudzuki, M., Hiroi, J., et al. (1997). Development of atopic dermatitis-like skin lesion with $\operatorname{IgE}$ hyperproduction in NC/Nga mice. Int Immunol, 9(3), 461-466.

Matsumoto, M., Kotani, M., Fujita, A., Higa, S., Kishimoto, T., Suemura, M., et al. (2002). Oral administration of persimmon leaf extract ameliorates skin symptoms and transepidermal water loss in atopic dermatitis model mice, NC/Nga. Br J Dermatol, 146(2), 221-227.

Metcalfe, A., Williams, J., McChesney, J., Patten, S. B., \& Jette, N. (2010). Use of complementary and alternative medicine by those with a chronic disease and the general population--results of a national population based survey. BMC Complement Altern Med, 10, 58.

Milden, S. P., \& Stokols, D. (2004). Physicians' attitudes and practices regarding complementary and alternative medicine. Behav Med, 30(2), 73-82. 
Miller, Alicia D, \& Eichenfield, Lawrence F. (2006). Evolving management of atopic dermatitis. Expert Review of Dermatology, 1(1), 31-41.

Miyanishi, K., Shiono, N., Shirai, H., Dombo, M., \& Kimata, H. (2005). Reduction of transepidermal water loss by oral intake of glucosylceramides in patients with atopic eczema. Allergy, 60(11), 1454-1455.

Molassiotis, A., Fernadez-Ortega, P., Pud, D., Ozden, G., Scott, J. A., Panteli, V., et al. (2005). Use of complementary and alternative medicine in cancer patients: a European survey. Ann Oncol, 16(4), 655-663.

Montoro, J., Sastre, J., Jauregui, I., Bartra, J., Davila, I., del Cuvillo, A., et al. (2007). Allergic rhinitis: continuous or on demand antihistamine therapy? I Investig Allergol Clin Immunol, 17 Suppl 2, 21-27.

Nakatsukasa, Hiroko, Tago, Fumitoshi, Okamoto, Takuya, Tsukimoto, Mitsutoshi, \& Kojima, Shuji. (2009). Therapeutic Effects of Gyokuheifusan on NC/Nga Mouse Model of Allergic Dermatitis. Journal of Health Science, 55(4), 516-524.

NCCAM. (2011). Exploring the science of complementary and alternative medicine : third strategic plan, 2011-2015. Bethesda, Md.: U.S. Dept. of Health and Human Services, National Institutes of Health.

Newman, D. J., \& Cragg, G. M. (2007). Natural products as sources of new drugs over the last 25 years. J Nat Prod, 70(3), 461-477.

Onishi, N., Kawamoto, S., Nishimura, M., Nakano, T., Aki, T., Shigeta, S., et al. (2004). The ability of konjac-glucomannan to suppress spontaneously occurring dermatitis in NC/Nga mice depends upon the particle size. Biofactors, 21(1-4), 163-166.

Onishi, N., Kawamoto, S., Nishimura, M., Nakano, T., Aki, T., Shigeta, S., et al. (2005). A new immunomodulatory function of low-viscous konjac glucomannan with a small particle size: its oral intake suppresses spontaneously occurring dermatitis in NC/Nga mice. Int Arch Allergy Immunol, 136(3), 258-265.

Onishi, N., Kawamoto, S., Suzuki, H., Santo, H., Aki, T., Shigeta, S., et al. (2007). Dietary pulverized konjac glucomannan suppresses scratching behavior and skin inflammatory immune responses in NC/Nga mice. Int Arch Allergy Immunol, 144(2), 95-104.

Onishi, N., Kawamoto, S., Ueda, K., Yamanaka, Y., Katayama, A., Suzuki, H., et al. (2007). Dietary pulverized konjac glucomannan prevents the development of allergic rhinitis-like symptoms and IgE response in mice. Biosci Biotechnol Biochem, 71(10), 2551-2556.

Oomizu, S., Onishi, N., Suzuki, H., Ueda, K., Mochizuki, M., Morimoto, K., et al. (2006). Oral administration of pulverized Konjac glucomannan prevents the increase of plasma immunoglobulin $\mathrm{E}$ and immunoglobulin $\mathrm{G}$ levels induced by the injection of syngeneic keratinocyte extracts in BALB/c mice. Clin Exp Allergy, 36(1), 102-110.

Pagan, J. A., \& Pauly, M. V. (2005). Access to conventional medical care and the use of complementary and alternative medicine. Health Aff (Millwood), 24(1), 255-262.

Park, E. J., Kim, B., Eo, H., Park, K., Kim, Y., Lee, H. J., et al. (2005). Control of IgE and selective $\mathrm{T}(\mathrm{H}) 1$ and $\mathrm{T}(\mathrm{H}) 2$ cytokines by PG102 isolated from Actinidia arguta. $J$ Allergy Clin Immunol, 116(5), 1151-1157.

Park, E. J., Park, K. C., Eo, H., Seo, J., Son, M., Kim, K. H., et al. (2007). Suppression of spontaneous dermatitis in NC/Nga murine model by PG102 isolated from Actinidia arguta. J Invest Dermatol, 127(5), 1154-1160. 
Passeron, T., Lacour, J. P., Fontas, E., \& Ortonne, J. P. (2006). Prebiotics and synbiotics: two promising approaches for the treatment of atopic dermatitis in children above 2 years. Allergy, 61(4), 431-437.

Peroni, D. G., Piacentini, G. L., Bodini, A., Rigotti, E., Pigozzi, R., \& Boner, A. L. (2008). Prevalence and risk factors for atopic dermatitis in preschool children. $\mathrm{Br} J$ Dermatol, 158(3), 539-543.

Pinnagoda, J., Tupker, R. A., Agner, T., \& Serup, J. (1990). Guidelines for transepidermal water loss (TEWL) measurement. A report from the Standardization Group of the European Society of Contact Dermatitis. Contact Dermatitis, 22(3), 164-178.

Presta, L. G., Lahr, S. J., Shields, R. L., Porter, J. P., Gorman, C. M., Fendly, B. M., et al. (1993). Humanization of an antibody directed against IgE. J Immunol, 151(5), 2623-2632.

Rapaport, M. H., Nierenberg, A. A., Howland, R., Dording, C., Schettler, P. J., \& Mischoulon, D. (2011). The treatment of minor depression with St. John's Wort or citalopram: Failure to show benefit over placebo. J Psychiatr Res, 45(7), 931-941.

Rawson, N. S. (2000). Time required for approval of new drugs in Canada, Australia, Sweden, the United Kingdom and the United States in 1996-1998. CMAJ, 162(4), 501-504.

Sakuma, S., Higashi, Y., Sato, N., Sasakawa, T., Sengoku, T., Ohkubo, Y., et al. (2001). Tacrolimus suppressed the production of cytokines involved in atopic dermatitis by direct stimulation of human PBMC system. (Comparison with steroids). Int Immunopharmacol, 1(6), 1219-1226.

Salameh, F., Perla, D., Solomon, M., Gamus, D., Barzilai, A., Greenberger, S., et al. (2008). The effectiveness of combined Chinese herbal medicine and acupuncture in the treatment of atopic dermatitis. J Altern Complement Med, 14(8), 1043-1048.

Scalbert, A., \& Williamson, G. (2000). Dietary intake and bioavailability of polyphenols. J Nutr, 130(8S Suppl), 2073S-2085S.

Schachner, L., Field, T., Hernandez-Reif, M., Duarte, A. M., \& Krasnegor, J. (1998). Atopic dermatitis symptoms decreased in children following massage therapy. Pediatr Dermatol, 15(5), 390-395.

Schafer, T. (2004). Epidemiology of complementary alternative medicine for asthma and allergy in Europe and Germany. Ann Allergy Asthma Immunol, 93(2 Suppl 1), S5-10.

Schafer, T., Riehle, A., Wichmann, H. E., \& Ring, J. (2002). Alternative medicine in allergies prevalence, patterns of use, and costs. Allergy, 57(8), 694-700.

Schempp, C. M., Ludtke, R., Winghofer, B., \& Simon, J. C. (2000). Effect of topical application of Hypericum perforatum extract (St. John's wort) on skin sensitivity to solar simulated radiation. Photodermatol Photoimmunol Photomed, 16(3), 125-128.

Schmitt, J., Meurer, M., Schwanebeck, U., Grahlert, X., \& Schakel, K. (2008). Treatment following an evidence-based algorithm versus individualised symptom-oriented treatment for atopic eczema. A randomised controlled trial. Dermatology, 217(4), 299-308.

Schrezenmeir, J., \& de Vrese, M. (2001). Probiotics, prebiotics, and synbiotics--approaching a definition. Am J Clin Nutr, 73(2 Suppl), 361S-364S.

SCORAD. (1993). Severity scoring of atopic dermatitis: the SCORAD index. Consensus Report of the European Task Force on Atopic Dermatitis. Dermatology, 186(1), 23-31.

Sewitch, M. J., \& Rajput, Y. (2010). A literature review of complementary and alternative medicine use by colorectal cancer patients. Complement Ther Clin Pract, 16(1), 52-56. 
Simpson, E. L., Berry, T. M., Brown, P. A., \& Hanifin, J. M. (2010). A pilot study of emollient therapy for the primary prevention of atopic dermatitis. J Am Acad Dermatol, 63(4), 587-593.

Sirois, F. M., \& Gick, M. L. (2002). An investigation of the health beliefs and motivations of complementary medicine clients. Soc Sci Med, 55(6), 1025-1037.

Spergel, J. M., \& Leung, D. Y. (2006). Safety of topical calcineurin inhibitors in atopic dermatitis: evaluation of the evidence. Curr Allergy Asthma Rep, 6(4), 270-274.

Stevens, S. R., Hanifin, J. M., Hamilton, T., Tofte, S. J., \& Cooper, K. D. (1998). Long-term effectiveness and safety of recombinant human interferon gamma therapy for atopic dermatitis despite unchanged serum IgE levels. Arch Dermatol, 134(7), 799804.

Streiner, DL , \& Normam, GL. (2009). Drug Trial Phases. Community Oncology, 6(1), 36-40.

Strunk, R. C., \& Bloomberg, G. R. (2006). Omalizumab for asthma. N Engl J Med, 354(25), 2689-2695.

$\mathrm{Su}, \mathrm{D} .$, \& Li, L. (2011). Trends in the use of complementary and alternative medicine in the United States: 2002-2007. J Health Care Poor Underserved, 22(1), 296-310.

Suto, H., Matsuda, H., Mitsuishi, K., Hira, K., Uchida, T., Unno, T., et al. (1999). NC/Nga mice: a mouse model for atopic dermatitis. Int Arch Allergy Immunol, 120 Suppl 1, 70-75.

Szczepanowska, J., Reich, A., \& Szepietowski, J. C. (2008). Emollients improve treatment results with topical corticosteroids in childhood atopic dermatitis: a randomized comparative study. Pediatr Allergy Immunol, 19(7), 614-618.

Teelucksingh, S., Mackie, A. D., Burt, D., McIntyre, M. A., Brett, L., \& Edwards, C. R. (1990). Potentiation of hydrocortisone activity in skin by glycyrrhetinic acid. Lancet, 335(8697), 1060-1063.

Tollesson, A., \& Frithz, A. (1993). Borage oil, an effective new treatment for infantile seborrhoeic dermatitis. Br J Dermatol, 129(1), 95.

Ukawa, Y., Ito, H., \& Hisamatsu, M. (2000). Antitumor effects of (1-->3)-beta-D-glucan and (1-->6)-beta-D-glucan purified from newly cultivated mushroom, Hatakeshimeji (Lyophyllum decastes Sing.). J Biosci Bioeng, 90(1), 98-104.

Ukawa, Y., Izumi, Y., Ohbuchi, T., Takahashi, T., Ikemizu, S., \& Kojima, Y. (2007). Oral administration of the extract from Hatakeshimeji (Lyophyllum decastes sing.) mushroom inhibits the development of atopic dermatitis-like skin lesions in NC/Nga mice. J Nutr Sci Vitaminol (Tokyo), 53(3), 293-296.

Y $\sigma \eta \alpha$ P $\alpha v \imath$, MYP N $\alpha \_\delta$. (2009). Phase 0 - Microdosing strategy in clinical trials. Indian Journal of Pharmacology, 40(6), 240-242.

Vestergaard, C., Yoneyama, H., Murai, M., Nakamura, K., Tamaki, K., Terashima, Y., et al. (1999). Overproduction of Th2-specific chemokines in NC/Nga mice exhibiting atopic dermatitis-like lesions. J Clin Invest, 104(8), 1097-1105.

Viljanen, M., Savilahti, E., Haahtela, T., Juntunen-Backman, K., Korpela, R., Poussa, T., et al. (2005). Probiotics in the treatment of atopic eczema/dermatitis syndrome in infants: a double-blind placebo-controlled trial. Allergy, 60(4), 494-500.

Wallach, D., Coste, J., Tilles, G., \& Taieb, A. (2005). The first images of atopic dermatitis: an attempt at retrospective diagnosis in dermatology. J Am Acad Dermatol, 53(4), 684689. 
WHO. (2005). National policy on traditional medicine and regulation of herbal medicines : report of a WHO global survey. Geneva: World Health Organization.

Wichers, H. (2009). Immunomodulation by food: promising concept for mitigating allergic disease? Anal Bioanal Chem, 395(1), 37-45.

Wiles, J., \& Rosenberg, M. W. (2001). 'Gentle caring experience'. Seeking alternative health care in Canada. Health Place, 7(3), 209-224.

Williams, H. (1992). Is the prevalence of atopic dermatitis increasing? Clin Exp Dermatol, 17(6), 385-391.

Williams, H. . (2003). Evening primrose oil for atopic dermatitis. BMJ, 327(7428), 1358-1359.

Wise, F., \& Sulzberger, MG. (1933). In Year Book of Dermatology and Syphiolology.

World Health Organization. (2009). Report of the WHO Interregional Workshop on the Use of Traditional Medicine in Primary Health Care : Ulaanbaatar, Mongolia, 23-26 August 2007. Geneva: World Health Organization.

Wright, S. (1991). Essential fatty acids and the skin. Br J Dermatol, 125(6), 503-515. 


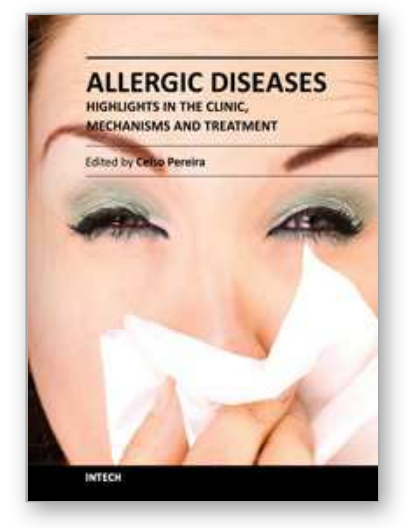

\author{
Allergic Diseases - Highlights in the Clinic, Mechanisms and \\ Treatment \\ Edited by Prof. Celso Pereira
}

ISBN 978-953-51-0227-4

Hard cover, 554 pages

Publisher InTech

Published online 14, March, 2012

Published in print edition March, 2012

The present Edition "Allergic diseases - highlights in the clinic, mechanisms and treatment" aims to present some recent aspects related to one of the most prevalent daily clinical expression disease. The effort of a group of outstanding experts from many countries reflects a set of scientific studies very promising for a better clinical care and also to the treatment and control of the allergy. This book provides a valuable reference text in several topics of the clinical allergy and basic issues related to the immune system response. The inflammatory reaction understanding in allergic disease is clearly evidenced, as well as new strategies for further researches.

\title{
How to reference
}

In order to correctly reference this scholarly work, feel free to copy and paste the following:

Clayton MacDonald and Marianna Kulka (2012). Natural Products and Dermatological Hypersensitivity Diseases, Allergic Diseases - Highlights in the Clinic, Mechanisms and Treatment, Prof. Celso Pereira (Ed.), ISBN: 978-953-51-0227-4, InTech, Available from: http://www.intechopen.com/books/allergic-diseaseshighlights-in-the-clinic-mechanisms-and-treatment/naturally-sourced-bioactives-are-a-promising-source-ofnovel-allergy-therapies

\section{INTECH}

open science | open minds

\author{
InTech Europe \\ University Campus STeP Ri \\ Slavka Krautzeka 83/A \\ 51000 Rijeka, Croatia \\ Phone: +385 (51) 770447 \\ Fax: +385 (51) 686166 \\ www.intechopen.com
}

\author{
InTech China \\ Unit 405, Office Block, Hotel Equatorial Shanghai \\ No.65, Yan An Road (West), Shanghai, 200040, China \\ 中国上海市延安西路65号上海国际贵都大饭店办公楼 405 单元 \\ Phone: +86-21-62489820 \\ Fax: +86-21-62489821
}


(C) 2012 The Author(s). Licensee IntechOpen. This is an open access article distributed under the terms of the Creative Commons Attribution 3.0 License, which permits unrestricted use, distribution, and reproduction in any medium, provided the original work is properly cited. 